\title{
A tribute to Richard S. Spielman
}

ichard Saul Spielman, the Thomas and Evelyn Butterworth Professor of Genetics at the University of Pennsylvania School of Medicine, died April 25, 2009, of an unexpected, overwhelming infection. Rich was the only child of the late Ralph Spielman, a childhood refugee from Nazi Germany who became a respected professor of social science at Bucknell University, and of Beatrice Spielman, a Democratic Party activist and adult Peace Corps volunteer. Rich received his undergraduate degree in biology from Harvard College in 1967 and MS and PhD degrees in human genetics at the University of Michigan, where he worked with James Neel on the population genetics of Native Americans of South America. While at Michigan, he participated in legendary field trips into the Amazon jungle with Neel. In 1974, he joined the faculty of the Department of Human Genetics (now Department of Genetics) at the University of Pennsylvania School of Medicine, where he remained for his entire career (Figure 1).

At Penn, Rich established a scientific program that focused on developing and testing statistical analytical tools and exploring questions in biochemical genetics. He also began his studies of the genetics of diabetes, the "geneticist's nightmare" as Neel famously called it, which he continued for over 25 years. A striking aspect of Rich's early work was that his collaborators, such as biochemical geneticist Harry Harris, pediatric diabetes specialist Lester Baker, and statistician Warren Ewens, became his lifelong friends.

After a year-long sabbatical in London with Walter Bodmer at what was then called the Imperial Cancer Research Fund, Rich returned to Penn in 1983 and launched a "wet bench" program to complement his statistical genetic efforts. From then on, his research was characterized by a successful integration of data generation and analysis.

Rich's scientific interests were many and varied. In addition to his research on type 1 diabetes (T1D) and polycystic ovary syndrome, his work in two other areas is highly cited and will continue to be so for years to come. The first of these was the transmission/disequilibrium test, which he developed with Ewens and is in wide use today (1, 2 ). This statistical method, a family-based test for allelic association in the presence of linkage, was immediately recognized as an important tool that provided a robust assess- ment of statistical significance, regardless of population stratification. The second of these is a relatively recent project, the genome-wide analysis of the genetic control of variation in gene expression, which Rich helped develop with Vivian Cheung, his colleague and collaborator who later became his wife (3-5).

Rich devoted a good portion of his research career to the study of T1D. In addition to the HLA and the insulin locus associations that Rich worked on for many years, the HapMap and high-throughput genotyping have revealed associations between T1D and alleles at over 30 more loci (6). For many of these loci, their role in disease susceptibility is unknown, because they are part of a link-

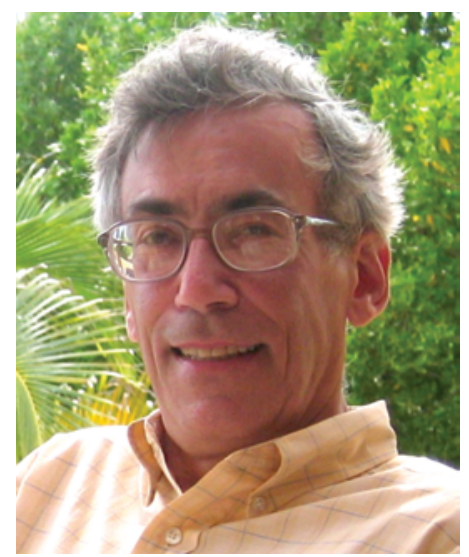

\section{Figure 1}

Rich Spielman during a moment of relaxation in the Caribbean.

age disequilibrium block with other alleles and sit within an intron or do not occur within any known gene. Even after additional genotyping and statistical analyses refine which alleles at which loci are responsible for the association, working out the mechanisms by which such variants affect disease risk requires functional genomic analyses based on a knowledge of gene regulation. The genome-wide analysis of the genetic control of variation in human gene expression, which Rich and his wife Vivian were pursuing over the past few years, is one approach that serves, along with others such as protein-protein or transcription factor-DNA interaction networks, to delineate the intricate pathways of gene regulation that we need if we are to understand complex human diseases.

What was it like to watch Rich at work? First, he was a scholar and a dyed-in-the-wool human geneticist who had great respect for the complexities and demands that human genetics makes on researchers who have the temerity to tackle problems in that discipline. He struck an intelligent balance between the wild-eyed naïveté of some "gene jockeys", who predicted that new technologies would quickly and easily solve the complex problems posed by human genetics, and the cynical skepticism of some statistical geneticists, disappointed too many times by false-positive results. Second, he brought intellectual playfulness to his research. He loved working with numbers and thinking with formulas, and he was precise in thought and language. Rich loved words as much as he loved numbers and formulas, and he both spoke and wrote with subtlety and grace. Third, he was funny in an unabashedly nerdy way that appealed to like-minded people. Finally, he enjoyed discussing his work with colleagues and students as much as he enjoyed doing the work. Together with his respect for math and love of language, his delight in engaging with others helped explain his aptitude for teaching and mentorship.

Rich was happy and busy working on a number of projects when his life was cut short. He is survived by his wife and scientific collaborator, Vivian Cheung, and his daughter by a previous marriage, Anita, as well as by his many colleagues, friends, and students. We all valued his many personal qualities and his friendship, advice, and intellectual generosity. Human geneticists of his caliber are rare and he will be sorely missed.

\section{Robert L. Nussbaum}

Institute for Human Genetics and Division of Medical Genetics, Department of Medicine, UCSF, San Francisco, California, USA.

1. Spielman, R.S., McGinnis, R.E., and Ewens, W.J. 1993. Transmission test for linkage disequilibrium: the insulin gene region and insulin-dependent diabetes mellitus (IDDM). Am. J. Hum. Genet. 52:506-516.

2. Ewens, W.J., and Spielman, R.S. 1995. The transmission/disequilibrium test: history, subdivision, and admixture. Am. J. Hum. Genet. 57:455-464.

3. Cheung, V.G., and Spielman, R.S. 2002. The genetics of variation in gene expression. Nat. Genet. 32(Suppl.):522-525.

4. Morley, M., et al. 2004. Genetic analysis of genomewide variation in human gene expression. Nature. 430:743-747.

5. Cheung, V.G., et al. 2005. Mapping determinants of human gene expression by regional and genomewide association. Nature. 437:1365-1369.

6. Concannon, P., Rich, S.S., and Nepom, G.T. 2009. Genetics of type 1A diabetes. N. Engl. J. Med. 360:1646-1654. 